\title{
Da senzala ao cortiço - história e literatura em Aluísio Azevedo e João Ubaldo Ribeiro
}

Regina Dalcastagnè Universidade de Brasília

\section{RESUMO}

0 artigo analisa dois romances brasileiros de épocas diferentes - 0 cortiço, de Aluísio Azevedo, lançado em 1890, e Viva o povo brasileiro, de João Ubaldo Ribeiro, de 1984. Apesar das muitas diferenças que os separam, ambos narram 0 processo de formação das elites brasileiras, revelando a violência nele envolvida. 0 naturalismo de Azevedo e o tom paródico de Ribeiro estabelecem, cada um a seu modo, um instigante diálogo com a história brasileira.

Palavras-chave: literatura e história; violência; elites.

\begin{abstract}
The article analyses two Brazilian novels, written in different epochs: Aluísio Azevedo's $O$ cortiço (The slum house), published in 1890, and João Ubaldo Ribeiro's Viva o povo brasileiro (translated as An invincible memory), of 1984. In spite of many differences, both relate the process of élites formation in Brazil, revealing its violence. Azevedo's naturalism and Ribeiro's use of parody establish, each one after its way, a stimulant dialogue with Brazilian history.

Keywords: literature and history; violence; elites.
\end{abstract}

Por que estás rindo? A história refere-se a ti, apenas o nome está mudado.

Horácio

O cortiço (1890), de Aluísio Azevedo, e Viva o povo brasileiro (1984), de João Ubaldo Ribeiro, são dois romances diferentes, com perspectivas e contextos afastados por quase 100 anos de história ${ }^{1}$. Se não são "romances históricos" no sentido mais restrito do termo (no caso, tão restrito que inviabilizaria a percepção das transformações do gênero), retratam, sem dúvida, um processo histórico, o da constituição das classes dominantes do Brasil. 0 primeiro situa sua trama no Rio de Janeiro do final do século XIX, quando se iniciava a modernização da cidade. Já o segundo abarca um período que vai de 1647 a 1972 e tem como cená- 
rio o Recôncavo Baiano. 0 naturalismo de um e o tom paródico e carnavalesco do outro não escondem a idêntica intenção de denúncia que os estrutura - Bahia e Rio de Janeiro podem ser lidos, portanto, como representações do Brasil por inteiro.

E essas representações - vinculadas ao determinismo do século 19 ou às novas perspectivas da História neste final de milênio - buscam alcançar justamente a luta pelo poder e por sua manutenção. Ou seja, pode-se dizer que a "formação das elites brasileiras" passa por dois momentos, que são esmiuçados e problematizados ao longo de 0 cortiço e Viva o povo brasileiro: o primeiro deles é o da conquista do poder por determinados grupos que, como veremos nos dois romances, se utilizaram basicamente da força bruta e do roubo. Após constituídos enquanto classes dominantes - possuidores de dinheiro e autoridade política - surge, num segundo momento, a necessidade de não só se manterem no poder, mas também de se elevarem socialmente, transformando-se em elites - possuidores de status e legitimidade. Para isso, empregam sobretudo a violência simbólica.

Apagam-se, assim, os traços do passado, eliminando da história os assassinatos, as traições, a perversidade utilizada para se alcançar o poder. Para completar, elimina-se ainda qualquer lembrança da mestiçagem original - e nossa elite passa a ser branca, honesta, religiosa e com bons costumes; além, é claro, de culturalmente preparada para assumir o comando, ontem, agora e sempre. Do outro lado, também esquecidas, apagadas da história, ficam as suas vítimas - mulheres, mestiços, negros, loucos, pobres todos eles. Aluísio Azevedo e João Ubaldo Ribeiro, ao descrever esse processo, resgatam nosso passado, nos fazem lembrar quem somos e, de certa forma, inscrevem suas obras na história, como uma resposta à violência simbólica exercida por nossas elites.

Serão analisadas, aqui, tanto a maneira como os dois autores enxergaram 0 processo de constituição das elites no Brasil — com seus variados mecanismos de violência - quanto as técnicas literárias empregadas por cada um deles para representá-lo.

\section{HISTÓRIA X FICÇÃO}

Uma vez que se estará falando aqui da leitura de fenômenos históricos a partir de sua representação ficcional, é necessário discutir sucintamente alguns pontos sobre a consagrada oposição entre história e ficção.

0 século 19, em sua ânsia desmistificadora e sua sede de verdade (que então era sinônimo de ciência), aboliu dos estudos da história o recurso às técnicas ficcionais de representação. Como lembra Hayden White, até antes da Revo- 
lução Francesa a historiografia era considerada uma arte narrativa e sua natureza literária era geralmente reconhecida, o que fazia com que obras de autores como Michelet fossem avaliadas tanto sob critérios científicos quanto literários. A oposição básica então era entre "verdade" e "erro", não entre fato e fantasia 2 . Foi no início do século 19 que "tornou-se convencional, pelo menos entre os historiadores, identificar a verdade com o fato e considerar a ficção o oposto da verdade, portanto um obstáculo ao entendimento da realidade e não um meio de apreendê-la. A história passou a ser contraposta à ficção, e sobretudo ao romance, como a representação do 'real' em contraste com a representação do 'possível' ou apenas do 'imaginável'”'.

Tudo isto, é claro, considerando-se que os fatos estão soltos por aí e que basta catalogá-los para que a verdade se faça, límpida e indiscutível, diante de nós. Contra tamanha certeza, poderíamos argumentar que os fatos não passam de versões sobre os fatos; que a sua descrição costuma envolver uma conseqüente e imediata interpretação; que nessa interpretação muitas vezes estão embutidos preconceitos de classe, de raça, de gênero (para falar só dos mais óbvios); que mesmo a linguagem utilizada para a descrição dos fatos é ideologicamente contaminada, politicamente comprometida. Sendo assim, nos perguntamos: nós, homens e mulheres deste final de século, onde se escondeu a verdade? Talvez a resposta não nos deixe mais tranqüilos, mas podemos nos sentir menos logrados: as verdades (já não é possível admitir o singular) estão sob camadas de interpretações e nós temos que assumir a responsabilidade de escolher os vários enfoques que podem ajudar a nos esclarecer. Esvai-se, aí, qualquer pretensão de imparcialidade, nossa ou daqueles que produzem os discursos sobre a realidade social.

Isto não significa equivaler história e ficção. Significa apenas entender que, embora em planos epistemológicos diferentes, ambas são aproximações à realidade que se fazem com a utilização de meios narrativos. Tampouco se está afirmando que todas as narrativas são idênticas, que nada está "errado". Algumas dessas aproximações são mais precisas ou mais significativas, outras menos romances ou narrativas históricas —, mas todas permanecem isto, aproximações; nenhuma esgota a realidade, são recortes, olhares.

\section{OS ROMANCES}

O livro de Aluísio de Azevedo comporta uma imensa galeria de personagens. $O$ cortiço do português João Romão é um organismo vivo, que nasce com algumas tábuas roubadas, e morre num incêndio. Nesse meio tempo, João Romão enriquece - explorando os miseráveis que moram ali e compram em sua 
venda, e a negra Bertoleza, sua companheira - e passa a sonhar com a ascensão social. Livra-se de Bertoleza, casa-se com a filha de Miranda - um comerciante português que se faz barão - e torna-se ele próprio visconde, apagando seu passado. 0 livro não se reduz, é claro, a essa trama (apesar de ser a que mais nos interessa aqui). Está em discussão toda a constituição da nação brasileira, através da miscigenação racial e cultural. Ao longo do romance, eivado dos preconceitos da época, vão aparecendo os diferentes modos de adaptação do português ao Brasil, além da luta dos negros e, especialmente, dos mestiços pela sobrevivência. Desse convívio de tipos vai se fazendo o romance, como ia se fazendo a nação.

João Ubaldo Ribeiro é bem mais explícito — já a partir do próprio título do romance - em sua intenção de falar da nação brasileira como um todo ${ }^{4}$. É da identidade nacional que o livro trata, identidade que também se constrói através da mestiçagem, da consciência da exploração, da luta sem glórias que não aparece na história. Pelas cerca de 700 páginas do romance transitam personagens quase épicas, gente que vai se transformando ao correr da narrativa, outros que são abjetos do começo ao fim. Os nomes mais importantes aqui são os de Perilo Ambrósio e Amleto Ferreira. 0 primeiro é uma figura rabelaisiana: glutão e destruidor, passa por cima de todos e de tudo para alcançar o que quer. 0 segundo é um mestiço arrivista, que começa como guarda-livros de Perilo Ambrósio, acaba se apoderando da fortuna do patrão e constituindo uma vasta e perene corja de herdeiros.

\section{OS PROTAGONISTAS}

Tanto Miranda e João Romão, de $O$ cortiço, quanto Perilo Ambrósio e Amleto, de Viva o povo brasileiro, são figuras que se complementam, representando momentos distintos nesse processo de constituição das elites brasileiras. Miranda foi o português que chegou antes, se adaptou rapidamente ao País, casouse com a filha do patrão e tornou-se rico. Vive num belo sobrado, ao lado do cortiço, odiando a mulher - que o trai desavergonhadamente - e a visão miserável que tem da janela. Não é preciso dizer mais sobre ele e sobre a forma como ascendeu socialmente porque essa parte de sua história vai ser, de alguma forma, repetida por João Romão. São seus passos, que se assemelham aos percorridos anteriormente por Miranda, que vamos acompanhar no romance.

Já o gordo e preguiçoso Perilo Ambrósio tem mais espaço dentro da narrativa - que é, por si só, bem mais extensa. Ao longo do romance, teremos muitas chances de observar toda a sua perfídia, que começa quando ele mata um escravo para sujar de sangue as próprias vestes, exibindo-se diante dos solda- 
dos brasileiros como um guerreiro ferido, herói da Independência do Brasil. (De quebra, ainda corta a língua do outro escravo que os acompanhava, para que a história jamais possa ser ouvida.) Aclamado herói da Pátria, Perilo ganha o título de barão de Pirapuama, além da fortuna. E assim prossegue sua história de desmandos e perversidades: "tinha no rosto tanta maldade indiferente, tanta crueza e tanta ausência de bom sentimento que sua baba, se caísse, poderia matar as plantas rasteiras e sua vontade era apenas a vontade de que tudo existisse para si, a vontade que não se pode bem distinguir da morte" (p. 92).

Em suma, é com uma falsa batalha e com sangue escravo que Perilo Ambrósio começa a conquistar poder. Fazendo-se rico com o beneplácito do imperador, ele se apodera de tudo que o cerca, consumindo cada vez mais sangue e mais mentiras, engordando de destruição. João Romão é uma versão mais urbana e menos carnavalesca dessa mesma ânsia pelo poder. Ele rouba, engana e explora para isso. Sua fortuna é amealhada com o logro dos miseráveis de seu cortiço - portugueses pobres, negros e mestiços livres que têm de entregar ao dono da estalagem e da venda quase todo o dinheiro que recebem no trabalho pesado da pedreira ou da lavação de roupas. Nesse aspecto, não eram menos escravos do que aqueles do barão de Pirapuama. Mas os tempos já eram outros.

De qualquer forma, também há sangue negro e escravo alimentando a fortuna de João Romão. Bertoleza, que entrega seu dinheiro para que o português compre sua liberdade (o que, é claro, ele não faz, mentindo-lhe e ficando com tudo), ajuda, com seu trabalho, na construção da riqueza de João Romão. No final, quando precisa se livrar da mulher que já não lhe cai bem, ele escreve para seus proprietários, dando notícias da "foragida". Antes de entregar-se, ela se mata, rasgando o ventre com uma faca e emborcando para a frente, "rugindo e esfocinhando moribunda numa lameira de sangue" (p. 224).

A nota de ironia fica por conta da chegada ao cortiço, no mesmo momento, de uma comissão de abolicionistas que "vinha, de casaca, trazer-lhe respeitosamente o diploma de sócio benemérito" (p. 224). 0 diploma entregue a João Romão é, de certa forma, o equivalente do título de barão que recebe Perilo Ambrósio - ou seja, a premiação de uma farsa. 0 que acaba acrescentando à violência física consumada por ambos a violência simbólica, de alguma maneira legitimada pela sociedade que os cerca. É a partir daí que Perilo e João Romão podem almejar ser mais do que donos de suas fortunas, senhores daqueles a quem exploram; podem sonhar fazer parte da elite que comanda o País.

\section{OS MOVIMENTOS}

Em suma, primeiro podemos observar um processo de espoliação, menti- 
ra, roubo, assassinato, fraude, estupro; depois, com a situação já estabelecida, a busca de títulos, os casamentos bem realizados, a construção de casas grandes e sofisticadas, os modos finos e os "bons sentimentos", com o conseqüente reconhecimento social. Em $O$ cortiço, tudo acontece de modo muito rápido. A história de Miranda, por exemplo, é interceptada pelo meio. Os movimentos que levaram o português até o sobrado, até o título de barão não são descritos, mas a figura está lá, sinalizando o ponto de chegada para o outro. É ele, João Romão, que observaremos alcançar o seu lugar — primeiro se arrastando, como o verme que efetivamente é, depois, erguido, esmagando os que estão em volta.

Em Viva o povo brasileiro, é com Amleto Ferreira que temos o movimento completo. Ele vem depois de Perilo Ambrósio, mas vai chegar muito mais longe. Perilo não deixa descendentes além daqueles nascidos de estupros; já Amleto, filho de uma professora negra e de um branco que desaparece, garante sua prole, que manterá seu nome, fortuna e poder. Amleto enriquece num processo lento, leva anos roubando nas contas e acaba comprando por quase nada as propriedades do falecido barão. Talvez se possa dizer que é mais sofisticado em seus crimes. Também investe mais em sua própria imagem, tentando parecer fino desde as iguarias consumidas em casa - no lugar do cuscuz, das broas de mi488 lho, do café com leite, os rins grelhados, o mingau com passas, o chá com torradas - até no nome, que de repente ganha acréscimos e origem nobre ${ }^{5}$.

João Romão faz o mesmo. Sujeito tosco que nunca havia gasto um centavo consigo próprio, ele aparece, ao final do livro, passeando pelos cafés cariocas como um verdadeiro janota. Mas a maior diferença entre os dois é que para Amleto, ao contrário de João Romão, não basta o respeito obtido pelo seu status social. Não bastam as roupas da moda, a casa rica, nem as servilidades dos que o cercam. Ele tem de convencer a si próprio, o tempo inteiro, de que é superior. A diferença real aqui está na cor da pele - Amleto é mestiço. Por mais que um comerciante português enfrentasse preconceitos no Brasil do século 19, nada se compararia com as dificuldades encontradas por um mulato na mesma época. E não só então.

Por isso o ex-guarda livros vai se fazendo cada vez mais branco ao longo dos anos. Seja através dos modos ingleses, que forja para si, seja através da prole, que embranquece com os casamentos "bem escolhidos". Afinal, se é preciso ser branco para ser elite, nada mais "natural" que se tornar branco. 0 auge desse processo se dá quando, gerações depois, um membro da família olha o retrato do trisavô, Amleto Henrique Nobre Ferreira-Dutton, e o vê "branco que parecia leitoso, o cabelo ralo e muito liso escorrendo pelos lados da cabeça, podia perfeitamente ser um inglês, como aliás, quase era, só faltou nascer na Inglaterra. Traços nórdicos visíveis” (p. 642). Para completar o retrato, uma biografia ex- 
tensa, que ressalta sua linha de conduta rígida, seus inquebrantáveis padrões éticos.

Fora isso, um pouco de lenda para tornar mais atraentes suas origens: o nome Dutton (inventado por Amleto), viria na verdade de Hutton, de uma família aparentada com a casa de Windsor. Sir George Hutton teria vindo ao Brasil por espírito de aventura e aqui se apaixonado pela jovem Ana Teresa, filha de mãe inglesa e pai brasileiro (mas nobre). Ela engravidou solteira, porém casou-se antes do nascimento do pequeno Amleto, morrendo, enfim, no parto. E é assim que d. Jesuína, pobre, negra e abandonada, se transforma numa figura branca, rica e um tanto mítica, ousada o suficiente para ser apreciada, mas comportada o bastante para não macular o nome da família. A outra aparece como uma empregada da casa - é considerado chique ter uma velha babá negra.

Não temos acesso a uma biografia do futuro visconde João Romão, mas certamente ela não diferiria muito da do aristocrático Amleto, principalmente no que diz respeito à integridade moral e à força de caráter. Quanto às suas origens, não faltariam nobres portugueses com histórias perdidas em velhas cartas e documentos mal conservados para esclarecer a sua estirpe. Eis aí nossa elite não seriam melhores se fossem autênticos, mas não custa arrancar-lhes algumas das máscaras, até porque também elas servem para oprimir.

\section{OS EXCLUÍDOS}

Reencenando seu passado, a classe dominante se faz elite, tão mais poderosa quanto mais sua ideologia estiver incorporada nas representações disseminadas do mundo social. Da cor da pele ao discurso sobre o "povo brasileiro", passando pela marcação da diferença em relação à culinária, ao modo de vestir, ou de falar, às "origens", tudo reafirma valores vinculados à conquista do poder como "qualidades naturais". Ou seja, aquilo que é apropriado como parte de uma estratégia de ascensão social é, em seguida, exposto como sendo uma qualidade natural. Como diz o sociólogo francês Pierre Bourdieu, na raiz do reconhecimento de qualquer forma de capital simbólico está o desconhecimento de sua substância e das maneiras pelas quais é adquirido ${ }^{6}$.

Esse desconhecimento está ligado, é claro, ao mascaramento da realidade - o retrato de Amleto e sua biografia, a fachada da nova estalagem de João Romão. Mas também tem a ver com o apagar de certas experiências ou existências - é a língua cortada de Feliciano, é a faca no ventre de Bertoleza. Nem um, nem a outra constariam em nossa história, não fosse o empenho recente de se rever o passado por outros ângulos. E não constariam ainda os escravos que vivem em torno de Perilo Ambrósio, de Amleto Ferreira, de João Romão e de Miranda, 
e as mulheres - brancas ou negras, ricas ou miseráveis, violentas ou violentadas, quase todas de alguma forma oprimidas. Não estariam ali os trabalhadores braçais, os pequenos comerciantes inescrupulosos, as jovens prostitutas e os loucos que vagam pelas ruas depois de lhes terem arrancado tudo.

Poderiam não estar nos livros de história, mas freqüentam nossa literatura desde o século passado. É que a história de João Romão não é a tal biografia de um visconde, mas a vida de um dono de cortiço no Rio de Janeiro do século 19 que consegue enriquecer e ganhar status social graças à exploração da miséria alheia. Sendo assim, não faria sentido nenhum esconder o que estava em sua volta. Muito pelo contrário, é essa gente - as prostitutas, os mendigos, as lavadoras de roupa, os malandros e bandidos - que conta a trajetória de João Romão, ao mesmo tempo em que fala de si própria, sem se deixar abafar pelo outro. Isso porque João Romão não é ele, mas o que representa: a elite brasileira, que não existe sozinha.

É assim também em relação a Amleto. Viva o povo brasileiro conta a história do "guardador de livros" mestiço que engana e rouba um outro ladrão e depois pensa que virou inglês. Mas essa não é a história contada por Amleto e seus descendentes, com seus documentos e álbuns de retratos, e sim pelo narrador do romance que, exterior à trama, ri e deforma. Aqui também, as dezenas de escravos, trabalhadores, bandidos e rufiões comparecem não para compor o pano de fundo, mas para dizer de si, para expressar a experiência do povo brasileiro, em contraponto à de suas elites. Por isso mesmo, junto à narrativa sobre Perilo Ambrósio e Amleto Ferreira corre uma outra: a da revolucionária Maria da Fé.

A história de Dafé não está subordinada à de Perilo e Amleto. Nasce ao mesmo tempo em que surge a exploração, ao mesmo tempo em que se ergue o primeiro braço de resistência. Filha da escrava Vevé e da violência do barão, Maria da Fé condensa em si os séculos de luta que a precederam e ainda os que virão depois. Como João Romão, Dafé é o que representa: o povo brasileiro, resultado de arbitrariedades e de sonhos, de derrotas e esperança. Por isso ela não poderia ser apresentada como uma simples vítima; tem que se transformar numa heroína mítica. Sua história não vai ser contada em livros e álbuns de retratos, mas pelo cego Faustino, que desconfia do que está escrito e constrói lendas a partir do vivido. E é assim, oralmente, com acréscimos e exageros, que essa trajetória de lutas vai se inscrever na memória popular, contrapondo-se à outra, resistindo ao esquecimento.

\section{TÉCNICAS E ESTILOS}

O cortiço e Viva o povo brasileiro fazem parte desse mesmo movimento de 
insubmissão. Ao contar a história da "formação das elites no Brasil”, Aluísio Azevedo e João Ubaldo Ribeiro trazem junto o questionamento do processo todo; inscrevendo-o na própria construção narrativa, ou simplesmente tornando esta matéria digna da literatura - o que acaba por lhe conferir legitimidade. $0 \mathrm{cu}$ rioso, aqui, é observar quanto os dois romances estão próximos apesar do "enorme" século que os separa: seja no emprego de alegorias, das personagens coletivas, daquelas que prosseguem em outras; seja nas situações armadas de maneira semelhante, muitas vezes caricatural; ou mesmo na utilização do grotesco ainda que as intenções em alguns desses casos possam ser bastante diferentes. Talvez isso sirva, antes de mais nada, para mostrar quanto o conteúdo pode moldar a forma do discurso literário.

Nem é preciso dizer que João Ubaldo Ribeiro incorpora ao seu texto uma série de processos técnicos alcançados ou consolidados pelos escritores neste último século. Muito especialmente no que se refere ao narrador. Ao contrário de Aluísio Azevedo - que, amparado no ideário naturalista, busca apresentar sua história de um ponto de vista (pretensamente) imparcial, com um narrador onisciente, que mantém sempre a "distância adequada" de seu objeto - Ubaldo cria um narrador implicado e em constante transformação. Seu espaço dentro da narrativa cresce ou diminui, de acordo com quem está presente na cena. Algumas vezes ele chega quase a desaparecer, dando lugar à voz do outro: como a da centenária Dadinha que, com a autoridade de mãe-de-santo somada à longa experiência de vida, passa a narrar, com sintaxe e vocabulário próprios, a história dos seus.

Em outros momentos, ele invade o texto, onisciente e corrosivo, abusado até. Não há como ter dúvidas sobre de que lado se encontra este narrador — ele se expõe, se exibe e ri, ri desavergonhadamente dos tiranos de plantão, carnavalizando-os e rebaixando-os. Neste sentido, a diferença em relação ao narrador de $O$ cortiço talvez seja apenas de tom. De início, poderíamos até achar que onde o primeiro utiliza o humor o outro lançaria mão da seriedade trágica, mas basta chegar mais perto, observar as entrelinhas que ouviremos ali o riso abafado, dissimulado do narrador de Aluísio Azevedo, que resguarda seu espaço dentro da narrativa, mas não se furta a usar da ironia destronante (o que volta a aproximar os dois narradores):

— Bandidos! berrava apoplético. Cáfila de salteadores!

E o seu rancor irradiava-lhe dos olhos em setas envenenadas, procurando cravar-se em todas as brancuras e em todas as claridades. A virtude, a beleza, o talento, a mocidade, a força, a saúde, e principalmente a fortuna, eis o que ele não perdoava a ninguém, amaldiçoando todo aquele que conseguia o que ele não obti- 
vera; que gozava o que ele não desfrutara; que sabia o que ele não aprendera (p. 25).

Em ambos os romances há uma tendência ao grotesco e ao caricatural, como se essa história não coubesse dentro de contornos mais sutis. Reduzir a opção de Aluísio Azevedo aos excessos do modelo naturalista seria muito pouco. Afinal, o exagero e o esquematismo sempre foram bastante convenientes para a fixação de uma narrativa. Lembrando dos termos de Walter Benjamin - que diferenciava narrativa de romance, vinculando a primeira às narrativas orais, com a transmissão de experiências e ensinamentos, e o segundo à obra de um indivíduo segregado, que não recebe nem dá conselhos ${ }^{7}$ - numa narrativa 0 ouvinte é livre para interpretar e acrescentar, mas para que ela funcione, para que seja memorizada e repetida, precisa contar com certos elementos, como a concisão, a renúncia a sutilezas psicológicas, os heróis e vilões bem definidos ${ }^{8}$.

Obviamente, nem Aluísio Azevedo nem João Ubaldo estavam fazendo narrativa oral, mas nada lhes impedia de empregar alguns de seus recursos para tornar mais eficaz sua mensagem. Não é o caso de Azevedo, mas Ubaldo chega mesmo a incorporar velhos narradores, como o cego Faustino - que conta a história de Maria da Fé e da canastra da Irmandade do Povo Brasileiro - , como uma forma de contraposição à história oficial. E ele retoma ainda um pouco da estrutura da narrativa oral: linguagem bastante referenciada na oralidade; poucas sutilezas psicológicas (com a exceção de Nego Leléu, e de momentos específicos de algumas personagens, como Henriqueta); bem e mal em posições determinadas; resgate da autoridade da morte (com os ensinamentos de Dadá, Patrício Macário e Nego Leléu); e ainda os constantes resumos no meio da narrativa, que serviriam para fixar as situações mais importantes.

Por outro lado, em ambos os romances o conjunto de personagens é manejado de forma semelhante. Os protagonistas não são indivíduos isolados, com personalidade diferenciada e única, mas uma composição de traços e características que os fazem representantes de determinada circunstância e momento histórico, além de uma espécie de continuidade de outras personagens, como já vimos em relação a Miranda e João Romão ou Perilo Ambrósio e Amleto. E isso não se dá só com os vilões - a heroína Maria da Fé também é constituída a partir da combinação de esboços e caracteres anteriores. Dafé é herdeira da coragem da mãe, Vevé; da sabedoria da avó Dadinha; até da decisão de $\mathrm{Vu}$, a comedora de gente que escolhe um holandês para seu próprio deleite.

São assim também, com outras medidas, a exuberante Rita Baiana de $O$ cortiço, representação dos "encantos" da mulata brasileira, e, principalmente, as prostitutas Léonie, Pombinha e a filha do português Jerônimo, que vão dando prosseguimento, com suas existências, a uma cadeia de exploração e misérias. 
Para além dos protagonistas, temos, nos dois romances, uma extensa e colorida gama de coadjuvantes. Alguns adquirem relevância vez ou outra, mas de resto são personagens coletivas - lavadeiras, escravos, trabalhadores livres, padres, soldados etc. - circulando por um espaço coletivo e participando de sua composição, sejam senzalas ou casas grandes, cortiços ou salões. Muitos deles poderiam, inclusive, transitar de um livro para o outro. Se Viva o povo brasileiro é mais rural (parte significativa dele se passa em fazendas), $O$ cortiço é integralmente urbano, mas ambos comportam as mesmas figuras - deformadas pelo cinismo, pelo riso ou pela idealização, mas ainda humanas.

Essa deformação é, a um só tempo, recurso e risco. Tanto pode lançar uma luz nova sobre aquilo que de tão conhecido já não se vê, quanto mutilar dramas e esconder preconceitos, simplificando o que é complexo para tentar expressar o indizível. Mas este é um conflito que se estende para além da literatura, envolvendo cada um que busca falar algo sobre o mundo. Nunca é demais repetir que Aluísio Azevedo e João Ubaldo Ribeiro escreveram seus livros dentro de determinado contexto histórico, o que não os redime, nem a nós. Afinal, essa história é nossa. 0 "nome mudado" não esconde nossas faces, nossos conflitos, nossa cumplicidade. Tentar fazer com que nos enxerguemos parece ser uma constante na literatura brasileira. Portanto, muito mais do que um mero reflexo da realidade, ela se propõe como diálogo - o que quer dizer que não basta olharmos o rosto que aparece ali, temos que dar uma resposta a ele.

\section{NOTAS}

${ }^{1}$ AZEVEDO, Aluísio. $O$ cortiço. S. Paulo: Círculo do Livro, 1987; RIBEIRO, João Ubaldo. Viva o povo brasileiro. Rio de Janeiro: Nova Fronteira, 1984. As referências aos romances serão dadas no corpo do texto.

${ }^{2}$ WHITE, Hayden. "As ficções da representação factual". In Trópicos do discurso. S. Paulo: Editora da Universidade Estadual de São Paulo, 1994, p. 139.

${ }^{3}$ Idem.

${ }^{4}$ A menos que entendamos que Aluísio Azevedo estava utilizando uma metonímia em seu título: o Brasil seria um cortiço?

${ }^{5}$ Por outro lado, talvez não seja apenas coincidência o fato de que Amleto era o nome do meio de Gino Meneghetti, o imigrante italiano que, na São Paulo do começo do século 20, conseguiu passar de bandido a herói através dos jornais.

${ }^{6}$ BOURDIEU, Pierre. Coisas ditas. Trad. de Cássia R. da Silveira e Denise Moreno Pegorim. S. Paulo: Brasiliense, 1990, p. 194.

${ }^{7}$ Cf. BENJAMIN, Walter. "O narrador. Considerações sobre a obra de Nikolai Leskov". In em 
Regina Dalcastagnè

Magia e técnica, arte e política. Trad. de Sergio Paulo Rouanet. 2ª ed. S. Paulo: Brasiliense, 1986, pp. 201-2.

${ }^{8}$ Idem, pp. $210-1$.

Artigo recebido em 08/2000. Aprovado em 03/2001.

Revista Brasileira de História, vol. 21, nº 42 